Air pollution and heart rate variability

\section{The way to dusty death?}

\section{J N Townend}

\section{"Environmental cardiology" - the relationship between air pollution, autonomic control, inflammation, and adverse cardiac events}

A s cardiologists know to their cost, the course of coronary artery disease is highly unpredictable. Although the disease accounts for about $20 \%$ of all deaths in developed countries and high levels of morbidity, in most cases the disease is clinically silent. Autopsy studies reveal that more than half of all people over the age of 60 and over a quarter of adults under this age have coronary artery disease. Even when this is manifest as angina, the annual event rate is only about $3 \%$. When adverse events occur, however, they usually do so without apparent cause and without warning. About half of the deaths due to coronary artery disease are sudden and, of these, half are due to plaque rupture and intracoronary thrombosis. ${ }^{1}$ In the remainder, although severe coronary artery disease is often present, no evidence of thrombus is found at autopsy and the cause of death is believed to be arrhythmic. If most adult residents of the western world are walking around with coronary artery disease, what are the factors that determine whether, on any given day, the disease remains silent or presents with an acute coronary syndrome or sudden arrhythmic death? Could external environmental factors increase the chances of plaque rupture or arrhythmia? If so, what are the mechanisms?

\section{AIR POLLUTION AND CORONARY ARTERY DISEASE}

Of the environmental factors examined, air pollution has become a prime suspect. While modern levels of particulate and gaseous pollutants are far lower than those of the 1950s, they continue to be related to daily total and cardiovascular mortality rates. ${ }^{2}$ A large number of papers from independent researchers in geographically and climatically distinct regions of the world have shown a consistent association between daily levels of pollution and cardiovascular mortality and morbidity including strokes, arrhythmia, and myocardial infarction. The effect size appears small; an increase of $10 \mu \mathrm{g} / \mathrm{m}^{3}$ in fine particulate pollution is associated with an increase of less than $1 \%$ in daily cardiovascular mortality (mean 24 hour levels in urban areas are usually about $20 \mu \mathrm{g} / \mathrm{m}^{3}$ but can approach 100$)$. On an individual level, this is an effect much smaller than smoking but, because it is an ever present stimulus to the entire population, the number of deaths attributable to this effect may be very large indeed.

Two areas of research into coronary artery disease have begun to shed light on the mechanisms by which air pollution might result in adverse cardiac events. Pulmonary inflammation as a result of air pollutant exposure might give rise to a systemic cytokine mediated inflammatory response. Atherosclerosis is an inflammatory disease and there is no doubt that there is a relationship between levels of inflammation and cardiovascular risk. An increase in C reactive protein (CRP) levels is predictive of cardiovascular risk in subjects with coronary artery disease and in apparently healthy subjects with or without conventional risk factors. ${ }^{3}$ Possible mechanisms include effects on plaque stability, endothelial function, platelet activation, and coagulation. A second mechanism by which airborne pollution might lead to adverse cardiac events is via adverse effects on cardiac autonomic control, either as a result of airway receptor stimulation or as an indirect consequence of an inflammatory response. There are robust data linking high levels of sympathetic tone and low levels of vagal control-as assessed by measurement of baroreflex sensitivity, heart rate variability and catecholamine levels-to mortality and the occurrence of arrhythmia in patients with heart failure, survivors of myocardial infarction, and even in healthy volunteer groups. ${ }^{4-6}$ There is also convincing evidence to suggest that this relationship is causal. Numerous animal studies have shown that sympathetic tone increases and vagal tone reduces the susceptibility to ventricular fibrillation. $^{7-9}$

In keeping with these inflammatory and autonomic hypotheses, observational studies have found that there are associations between daily levels of particulate pollution and markers of both inflammation and heart rate variability (HRV). Levels of CRP and plasma viscosity increased during an episode of pollution in Germany in 1985 that was also associated with a dramatic increase in hospital admissions for cardiac events. ${ }^{10}$ During the same episode heart rates were increased, suggesting an increase in sympathetic nervous activity and/or vagal withdrawal. Subsequently, small panel studies from Boston, ${ }^{11}$ Baltimore, ${ }^{12}$ and Utah ${ }^{13}$ supported this interpretation, finding that HRV was reduced during particulate pollution episodes. More recently, larger studies from Mexico ${ }^{14}$ and from $\mathrm{Utah}^{15}$ have shown that high frequency (vagal) components of HRV vary inversely with levels of particulate matter less than $2.5 \mu \mathrm{m}$ in diameter $\left(\mathrm{PM}_{2.5}\right)$, particularly in at risk subjects with hypertension. A human challenge study has also shown that experimental exposure to concentrated ambient particles results in reduced HRV. ${ }^{16}$

Two new papers that further investigate the relationship between ambient pollutant concentrations and HRV are published in this issue of Thorax. ${ }^{17} 18$ Once again they are small studies with fewer than 40 subjects in each case. What new information do these papers provide? Schwartz and colleagues ${ }^{17}$ working in Boston examined the effect of locally measured pollutants on HRV and confirmed the results of their earlier study, showing an inverse association between the preceding 24 hour average $\mathrm{PM}_{2.5}$ and high frequency HRV indices of cardiac vagal control such as r-MSSD. A weaker effect on SDNN, a measure of total variability that includes nonautonomic influences, was observed. In a sophisticated analysis they found that the effects of black carbon were slightly greater in magnitude than those of $\mathrm{PM}_{2.5}$, and that these effects were present in all individuals studied although they were strongest in the three subjects with a previous myocardial infarction. The study is perhaps best viewed as hypothesis generating, but it does suggest that traffic related particles exert even more powerful adverse effects on cardiac autonomic control than $\mathrm{PM}_{2.5}$ which, in Boston, is composed predominantly of long range transported sulphates probably derived from industrial emissions. This result accords with a recent report that implicates exposure to traffic as a trigger of myocardial infarction. ${ }^{19}$ It is also consistent with the hypothesis that subjects with coronary artery disease are at particular risk from the adverse effects of air pollution. 
In contrast, Sullivan and colleagues ${ }^{18}$ working in Seattle found no association between 1, 4 or 24 hour outdoor or indoor exposure to particulate matter and any frequency or time domain measure of HRV in 24 elderly individuals monitored over 10 day periods. These results are in disagreement with previous published work. Publication bias cannot be excluded as an explanation for the absence of previous negative studies, but could there be methodological or other features of this study that might explain the negative results? Unlike most previous reports, the measurement of particulates was performed at each individual's home rather than at a local monitoring station. However, this should be viewed as a major strength of the study and it is hard to see how this could have been responsible for anything other than increasing the strength of any association with HRV values. The study was performed on the western coast of the United States and the authors speculate that the particulate pollution in this region may differ in its composition from that of previous studies in other areas. There is evidence that the toxicity of particulate pollution is related to the content of reactive metal species and sulphates. The particles in Seattle may have contained lower levels of these toxic components than those from regions such as Boston and Baltimore, although no information on this is given in the paper. A more likely explanation, however, may lie in the combination of low PM values and the small range of concentrations encountered. It is possible that there were simply too few periods of high exposure to cause any detectable effects on HRV and this, in turn, is probably a reflection of the short 10 day study periods. A further factor could be the inclusion of 21 patients with cardiovascular disease in the study, a large proportion of whom were on drugs such as $\beta$ blockers and ACE inhibitors known to increase HRV and preserve vagal tone under conditions of stress. ${ }^{20}$

The relationship between air pollution and both autonomic control and inflammation clearly requires further study. There is, however, a key piece of evidence missing in both of these mechanistic theories. Paradoxically, the prognostic value of both HRV and CRP is established for medium and long term associations but not for short term effects over hours or days. Unless it can be shown that changes in these markers precede adverse events within an appropriate time scale, the significance of reports of changes in response to day to day fluctuations in pollutant levels must remain in doubt. On biological grounds both mechanisms appear plausible. An inflammatory cytokine response resulting in a rise in $\mathrm{CRP}$ occurs within hours in response to infection, inflammation, and tissue damage-events that occur frequently throughout life. Similarly, sympathetic and cardiac vagal activities vary constantly in response to reflex stimuli, emotion, exertion and, of course, inflammation and infection. Support for the concept also comes from the recent reports that CRP varies markedly over time in patients with coronary artery disease, ${ }^{21}$ even when clinical infective episodes are excluded, and from the finding that acute respiratory and urinary tract infections are associated with a transient increase in the risk of a stroke and myocardial infarction. ${ }^{22}$ In addition, a small study of patients with heart failure showed that cases of sudden death were preceded by intra-individual increases in CRP and falls in HRV. ${ }^{23}$ As the American Heart Association has recognised in their recent statement, further research on the relationship between air pollution, autonomic control, inflammation, and adverse cardiac events is required. ${ }^{2}$ Funding bodies should be aware of this new field that has been termed "environmental cardiology". The results of research could be of immediate value to people with coronary disease-and this includes most of us!

Thorax 2005;60:441-442.

doi: 10.1136/thx.2004.037903

Correspondence to: $\mathrm{Dr} J \mathrm{~N}$ Townend, Queen Elizabeth Hospital, Birmingham B15 2TH, UK; john.townend@uhb.nhs.uk

\section{REFERENCES}

1 Virmani R, Burke AP, Farb A. Sudden cardiac death. Cardiovasc Pathol 2001;10:211-8.

2 Brook RF, Cascio B, Hong W, et al. Air pollution and cardiovascular disease: a statement for healthcare professionals from the expert panel on population and prevention science of the American Heart Association. Circulation 2004; 109:2655-71

3 Ridker PM. Clinical application of C-reactive protein for cardiovascular disease detection and prevention. Circulation 2003;107:363-9.

4 Nolan J, Batin PD, Andrews R, et al. Prospective study of heart rate variability and mortality in chronic heart failure: results of the United
Kingdom heart failure evaluation and assessment of risk trial (UK-Heart). Circulation 1998:98:1510-6.

5 La Rovere M, Bigger JT Jr, Marcus Fl, et al. Baroreflex sensitivity and heart-rate variability in prediction of total cardiac mortality after myocardial infarction. ATRAMI (Autonomic Tone and Reflexes After Myocardial Infarction) Investigators. Lancet 1998;351:478-84.

6 Tsuji H, Larson MG, Venditti FJ Jr, et al. Impact of reduced heart rate variability on risk for cardiac events. The Framingham Heart Study. Circulation 1996:94:2850-5.

7 Vanoli E, De FGM, Stramba-Badiale M, et al. Vagal stimulation and prevention of sudden death in conscious dogs with a healed myocardial infarction. Circ Res 1991;68:1471-81.

8 Schwartz P, Vanoli E, Stramba-Badiale M, et al. Autonomic mechanisms and sudden death. New insights from analysis of baroreceptor reflexes in conscious dogs with and without a myocardial infarction. Circulation 1988;78:969-79.

9 Lown B, Verrier RL. Neural activity and ventricular fibrillation. N Engl J Med 1976;294:1 165-70.

10 Peters A, Frohlich M, Doring A, et al. Particulate air pollution is associated with an acute phase response in men; results from the MONICAAugsburg Study. Eur Heart $J$ 2001;22:1198-204

11 Gold DR, Litonjua A, Schwartz J, et al. Ambient pollution and heart rate variability. Circulation 2000;101:1267-73.

12 Creason J, Neas L, Walsh D, et al. Particulate matter and heart rate variability among elderly retirees: the Baltimore 1998 PM study. J Expos Anal Environ Epidemiol 2001;11:116-22.

13 Pope CA 3rd, Verrier RL, Lovett EG, et al. eart rate variability associated with particulate air pollution. Am Heart J 1999; 138:890-9.

14 Holguin F, Tellez-Rojo MM, Hernandez M, et al. Air pollution and heart rate variability among the elderly in Mexico City. Epidemiology 2003; 14:521-7.

15 Pope CA 3rd, Hansen ML, Long RW, et al. mbient particulate air pollution, heart rate variability, and blood markers of inflammation in a panel of elderly subjects. Environ Health Perspect 2004; 112:339-45

16 Devlin RB, Ghio AJ, Kehrl H, et al. Elderly humans exposed to concentrated air pollution particles have decreased heart rate variability. Eur Respir J 2003;21:76-80s.

17 Schwartz J, Litonjua A, Suh H, et al. Traffic related pollution and heart rate variability in a panel of elderly subjects. Thorax 2005;60:455-61.

18 Sullivan JH, Schreuder A, Trenga C, et al. Association between short term exposure to fine particulate matter and heart rate variability in older subjects with and without heart disease. Thorax 2005;60:462-6.

19 Peters $\mathbf{A}$, von Klot S, Heier $M$, et al. Exposure to traffic and the onset of myocardial infarction. N Engl J Med 2004;351:1721-30.

20 Vaile JC, Fletcher J, Al-Ani M, et al. Use of opposing reflex stimuli and heart rate variability to examine the effects of lipophilic and hydrophilic beta-blockers on human cardiac vagal control. Clin Sci 1999;97:585-93; discussion 609-10.

21 Bogaty P, Brophy JM, Boyer L, et al. Fluctuating inflammatory markers in patients with stable ischemic heart disease. Arch Intern Med 2005; 165:221-6.

22 Smeeth L, Thomas SL, Hall AJ, et al. Risk of myocardial infarction and stroke after acute infection or vaccination. N Engl J Med 2004;351:2611-8

23 Shehab AM, MacFadyen RJ, McLaren M, et al. Sudden unexpected death in heart failure may be preceded by short term, intraindividual increases in inflammation and in autonomic dysfunction: a pilot study. Heart 2004;90:1263-8. 
The endothelin system in pulmonary arterial hypertension

\section{The endothelin system and its role in pulmonary arterial hypertension (PAH)}

\section{J Pepke-Zaba, N W Morrell}

Endothelin receptor antagonists represent a major advance in the treatment of PAH but much remains to be learned of their effectiveness in specific forms of pulmonary hypertension

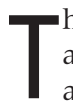
he endothelin system is emerging as an important mediator in pulmonary arterial hypertension (PAH) and the endothelin receptor antagonists represent a major advance in the treatment of this condition. PAH results from a massive proliferation of myofibroblast cells in the intima of small pulmonary arteries. Thickening of the media is also observed and abnormal proliferation of endothelial cells may result in plexiform lesions.

The endothelin system has been extensively studied over the 15 years since its initial discovery by Yanagisawa and co-workers in 1988. It is clear that endothelin 1 (ET-1) is a key mediator of pulmonary vascular biology and pathophysiology. It is a powerful vasoconstrictor and proliferative cytokine. In the early 1990s ET-1 was identified as an important mediator of PAH. Plasma ET1 levels were found to be elevated in patients with pulmonary hypertension and correlated with the raised pulmonary vascular resistance. ${ }^{1}$ Furthermore, expression of ET-1 mRNA and protein was increased in endothelial cells comprising vascular lesions in primary pulmonary hypertension. ${ }^{2}$

The availability of ET-1 receptor antagonists allowed testing of these compounds in experimental models. In rat models of experimental pulmonary hypertension-including pulmonary hypertension induced by chronic (23 weeks) hypoxia ${ }^{3}$ and by the alkaloid monocrotaline-ET-1 antagonists prevent the development of PAH. More compelling is the finding that ET-1 antagonists can partly reverse established PAH in experimental models. ${ }^{4}$ These observations suggest that ET-1 antagonists can potentially reverse established pulmonary vascular remodelling rather than simply prevent vasoconstriction. ${ }^{5}$ In clinical PAH the main component of the increased pulmonary vascular resistance is remodelling rather than vasoconstriction. However, in animal models the predominant lesion is medial hypertrophy rather than intimal thickening, and it is unknown whether regression of these lesions occurs in man. Nevertheless, ET-1 antagonists provide a unique opportunity to target pulmonary vascular remodelling via their effects on vascular cell growth.

\section{ENDOTHELIN RECEPTORS}

Endothelin receptors exist in at least two separate isoforms, $\mathrm{ET}_{\mathrm{A}}$ and $\mathrm{ET}_{\mathrm{B}}$. $\mathrm{ET}_{\mathrm{A}}$ receptors are generally present on smooth muscle cells and are responsible for vasoconstriction and cell proliferation whereas $\mathrm{ET}_{\mathrm{B}}$ receptors are found on both endothelial cells and smooth muscle cells. The role of $\mathrm{ET}_{\mathrm{B}}$ receptors is more complex. $\mathrm{ET}_{\mathrm{B}}$ receptor can mediate endothelium-dependent vascular relaxation by inducing nitric oxide (NO) and prostacyclin $\left(\mathrm{PGI}_{2}\right)$ release and are therefore thought to induce vasodilatation; however, the potential of $\mathrm{ET}_{\mathrm{B}}$ receptors to mediate relaxation is not clear. The proportion of $\mathrm{ET}_{\mathrm{B}}$ receptors increases in small peripheral pulmonary arteries. ${ }^{6}$ It is this peripheral region comprising the resistance arteries of the lung that is the most important site for vascular remodelling in PAH. Pharmacological studies in human pulmonary resistance arteries suggest that the $\mathrm{ET}_{\mathrm{B}}$ receptor, as well as the $\mathrm{ET}_{\mathrm{A}}$ receptor, mediate vasoconstriction to ET-1 in man, although there appear to be species differences in $\mathrm{ET}_{\mathrm{B}}$ mediated contraction. Human pulmonary artery smooth muscle cells cultured from small pulmonary arteries $(<1 \mathrm{~mm}$ external diameter) retain a high proportion of $\mathrm{ET}_{\mathrm{B}}$ binding (33\%) and these receptors can be shown to mediate some of the growth response to ET- $1 .{ }^{6}$ Patients with severe pulmonary hypertension exhibit increased ET receptor binding in peripheral pulmonary arteries. ${ }^{6}$ In patients with idiopathic pulmonary arterial hypertension (previously known as primary pulmonary hypertension) there appeared to be no change in the proportion of $\mathrm{ET}_{\mathrm{A}}: \mathrm{ET}_{\mathrm{B}}$ receptors in peripheral pulmonary arteries as assessed by in vitro autoradiography. ${ }^{6}$
However, in chronic thromboembolic pulmonary hypertension, selective upregulation of $\mathrm{ET}_{\mathrm{B}}$ receptor mRNA has been reported in lung samples. ${ }^{7}$ Thus, a case has been made for dual $\mathrm{ET}_{\mathrm{A}} / \mathrm{ET}_{\mathrm{B}}$ receptor antagonists in the inhibition of pulmonary vascular remodelling. Since ET-1 is produced by the neighbouring endothelium and in an autocrine manner by smooth muscle cells in the vascular wall, dual $\mathrm{ET}_{\mathrm{A}} / \mathrm{ET}_{\mathrm{B}}$ receptor antagonism could block both receptor subtypes shown to be involved in ET-1 stimulated smooth muscle cell proliferation. Inhibition of $\mathrm{ET}_{\mathrm{B}}$ receptors on the endothelium could theoretically be detrimental because of the loss of $\mathrm{ET}_{\mathrm{B}}$ mediated $\mathrm{NO} / \mathrm{PGI}_{2}$ release, although in vivo this effect has not been observed and the relative benefits of dual $\mathrm{ET}_{\mathrm{A}} / \mathrm{ET}_{\mathrm{B}}$ versus $\mathrm{ET}_{\mathrm{A}}$ antagonism remain to be determined.

\section{THERAPEUTIC POTENTIAL OF ENDOTHELIN RECEPTOR ANTAGONISTS}

The critical importance of ET-1 in the spectrum of pulmonary hypertensive disorders has identified endothelin receptor antagonists as having obvious therapeutic potential. The oral dual endothelin receptor antagonist bosentan (Tracleer) has been studied in two randomised, placebo controlled, double blind studies. ${ }^{89}$ Patients with $\mathrm{PAH}$ (idiopathic or associated with connective tissue disease) in NYHA functional class III or IV were included. The primary end point (6 minute walking distance) was evaluated at 16 weeks. Patients treated with bosentan walked 36.4 metres further at 16 weeks compared with a reduction in walking distance of 7.8 metres in the placebo group, giving a treatment effect of 44.2 metres (CI 21 to 67 metres, $p=$ 0.0002). Clinical worsening-defined by death, premature withdrawal from study, admission to hospital for worsening of $\mathrm{PAH}$, or escalation of treatment to intravenous prostacyclin-occurred in $37 \%$ of placebo treated patients compared with $11 \%$ of bosentan treated patients $(p=0.0015)$. NYHA functional class improved significantly in more patients on bosentan than placebo.

An open label, uncontrolled, single and multiple dose study has been performed in children aged 4-17 years with PAH to assess the pharmacokinetics, tolerability, and safety of oral bosentan. In this preliminary study a significant improvement in haemodynamics was observed after 12 weeks of bosentan treatment in the 18 enrolled children, either alone or in combination with intravenous epoprostenol. ${ }^{10}$

Favourable clinical and haemodynamic results have recently been achieved with the use of bosentan in 
11 patients with HIV-associated PAH. ${ }^{11}$ A study to assess the effects of bosentan in patients with Eisenmenger's disease is also ongoing.

The most important adverse event described in patients taking bosentan is an increase in serum hepatic transaminase levels in $11 \%$ of patients. Abnormal hepatic function was found to be dose dependent, being more frequently reported in patients receiving $250 \mathrm{mg}$ twice daily or higher than in those receiving $125 \mathrm{mg}$ twice daily (14\% and $5 \%$, respectively). Due to the potential increase in liver enzymes, the US Food and Drug Administration (FDA) requires that liver function tests be performed at least monthly. Bosentan use may also be associated with mild anaemia.

Careful attention must be paid to the use of adequate contraception in women of childbearing age because of potential teratogenic effects. In addition, bosentan may decrease the efficacy of hormonal contraceptive techniques and, for this reason, they should not be used alone. There is concern that the endothelin antagonists as a class may be capable of causing testicular atrophy and male infertility. Younger men who may consider conceiving should be counselled regarding this possibility before taking these drugs.

Most recent data from two randomised, placebo controlled studies and two long term extensions show that bosentan treated patients in NYHA class III have improved survival at 2 years compared with that estimated by NIH equation. $^{12}$

Bosentan has been approved for the treatment of NYHA class III and IV PAH in the USA and Canada. In Europe it has been approved by the EMEA for the treatment of NYHA class III PAH, specifying that efficacy has been demonstrated only in patients with IPAH patients and those with $\mathrm{PAH}$ associated with scleroderma without significant lung fibrosis.

The success of bosentan has seen the emergence of further endothelin receptor antagonists for the treatment of pulmonary hypertension. These include the selective $\mathrm{ET}_{\mathrm{A}}$ receptor antagonists sitaxsentan $^{13} 14$ and ambrisentan ${ }^{15}$ which are currently undergoing phase III clinical trials. There is much debate as to whether $\mathrm{ET}_{\mathrm{A}}$ selectivity or dual $\mathrm{ET}_{\mathrm{A}} / \mathrm{ET}_{\mathrm{B}}$ blockade possesses any clinical advantage. Sitaxsentan, a selective orally active $\mathrm{ET}_{\mathrm{A}}$ receptor antagonist, has a long duration of action (half life
5-7 hours) and is approximately 6500 times more selective as an antagonist for $\mathrm{ET}_{\mathrm{A}}$ than for $\mathrm{ET}_{\mathrm{B}}$ receptors. It has been assessed in one randomised clinical trial on 178 patients with PAH in NYHA class II, III and IV. The study showed improvements in exercise capacity compared with placebo, increased 6 minute walking distance of 35 metres and 33 metres with doses of $100 \mathrm{mg}$ and $300 \mathrm{mg}$, respectively $(\mathrm{p}<0.01)$, haemodynamics and clinical events. ${ }^{14}$ An additional pilot study with this compound in 20 patients with PAH has shown similar results. ${ }^{13}$ However, a recent study showed an increase in the 6 minute walking distance of 65 metres $(p=0.0002)$ in patients with PAH in NYHA class III and IV. ${ }^{15}$ As with bosentan, liver function abnormalities occurred with sitaxsentan $(10 \%$ in the $300 \mathrm{mg}$ group) ${ }^{13}$

Ambrisentan, another selective orally active $\mathrm{ET}_{\mathrm{A}}$ receptor antagonist, has been evaluated in a pilot blinded dose comparison study in 64 patients with PAH. ${ }^{16}$ Two randomised clinical trials are currently ongoing.

Clearly, endothelin receptor antagonists represent a major advance in the treatment of PAH. However, much remains to be learned of their effectiveness in specific forms of pulmonary hypertension-for example, patients with inoperable chronic thromboembolic pulmonary hypertension.

As with systemic hypertension, it is likely that the optimum approach in pulmonary hypertension will involve the use of drug combinations, so more information is needed on the combined effects of endothelin receptor antagonists with other emerging and available treatments. ${ }^{17}$ In addition, we need to know whether these agents could prevent the progression of disease in patients with NYHA I/II symptoms.

The studies with the orally active nonselective endothelin receptor antagonist bosentan are a welcome addition to our therapeutic formulary. Early data on selective $\mathrm{ET}_{\mathrm{A}}$ blockade are encouraging and may result in alternative treatments.

Thorax 2005;60:443-444. doi: $10.1136 /$ thx.2004.031724

\section{Authors' affiliations}

J Pepke-Zaba, Papworth Hospital, Cambridge, UK

N Morrell, University of Cambridge School of Clinical Medicine, Addenbrooke's and Papworth Hospitals, Cambridge, UK
Correspondence to: Dr J Pepke-Zaba, Pulmonary Vascular Diseases Unit, Papworth Hospital, Cambridge CB3 8RE, UK; ijm.zaba@ ntlworld.com

\section{REFERENCES}

1 Stewart DJ, Levy RD, Cernacek P, et al. Increased plasma endothelin-1 in pulmonary hypertension: marker or mediator of disease. Ann Intern Med 1991:114:464-9.

2 Giaid A, Yanagisawa M, Langleben D, et al. Expression of endothelin- 1 in the lungs of patients with pulmonary hypertension. N Engl J Med 1993:328:1732-9.

3 Bonvallet ST, Zamora MR, Hasunuma, et al. $B Q 123$, an $E_{A}$-receptor antagonist, attenuates hypoxic pulmonary hypertension in rats. Am J Physiol 1994:266:H1327-1.

4 Miyauchi T, Yorikane R, Sakai S, et al. Contribution of endogenous endothelin- 1 to the progression of cardiopulmonary alterations in rats with monocrotaline-induced pulmonary hypertension. Circ Res 1993;73:887-97.

5 Chen S-J, Chen Y-F, Opgenorth TJ, et al. The orally active nonpeptide endothelin $A$ receptor antagonist A-127722 prevents and reverses hypoxia-induced pulmonary hypertension and pulmonary vascular remodelling in SpragueDawley rats. J Cardiovasc Pharmacol 1997;29:713-2.

6 Davie N, Haleen SJ, Upton PD, et al. ETA and ETB receptors modulate the proliferation of human pulmonary artery smooth muscle cells. Am J Respir Crit Care Med 2002; 165:398-405.

7 Baver M, Wilkens $H$, Langer $F$, et al. Selective upregulation of endothelin $B$ receptor gene expression in severe pulmonary hypertension. Circulation 2002; 105:1034-6.

8 Channick R, Simonneau G, Sitbon O, et al. Effects of the dual endothelin receptor antagonist bosentan in patients with pulmonary hypertension: a randomised placebo-controlled study. Lancet 2001;358:1119-23.

9 Rubin LJ, Badesch DB, Barst RJ, et al. Bosentan therapy for pulmonary arterial hypertension. N Engl J Med 2002;346:896-903.

10 Barst R, Ivy D, Widlitz AC, et al. Pharmacokinetics, safety, and efficacy of bosentan in pediatric patients with pulmonary arterial hypertension. Clin Pharmacol Ther 2003:73:372-82.

11 Sitbon O, Gressin V, Speich R, et al. Bosentan in pulmonary arterial hypertension associated with HIV infection. Eur Respir J 2003;22:563

12 McLaughlin V, Sitbon O, Rubin U, et al. The effect of first-line bosentan on survival of patients with primary pulmonary hypertension. Am J Respir Crit Care Med 2003; 167:A442.

13 Barst RJ, Rich S, Widlitz A, et al. Clinical efficacy of sitaxsentan, an endothelin-A receptor antagonist, in patients with pulmonary arteria hypertension: open-label pilot study. Chest 2002;121:1860-8.

14 Barst RJ, Langleben D, Frost A, et al. Sitaxsentan therapy for pulmonary arterial hypertension. Am J Respir Crit Care Med 2004; 169:441-7.

15 Frost $A$, Langleben $D$, Hill NS, et al. $6 \mathrm{MW}$ as an efficacy endpoint in $\mathrm{PAH}$ clinical trials: demonstration of a ceiling effect. Am J Respir Crit Care Med 2004; 169:A176.

16 Rubin L, Galie N, Badesch BD, et al. Ambrisentan improves exercise capacity and clinical measures in pulmonary arterial hypertension (PAH). Am J Respir Crit Care Med 2004; (in press).

17 Humbert M, Barst RJ, Robbins IM, et al. Combination of bosentan with epoprostenol in pulmonary arterial hypertension: Breathe-2. Eur Respir J 2004;24:353-9. 